\title{
Postoperative Clinical Outcomes of Colonic Stent Placement as Bridge-to-surgery vs. Emergency Surgery in Left-sided Malignant Colonic Obstruction
}

\author{
Eun Ju Choe, Yong Kang Lee, Han Ho Jeon, Jong Won Choi, Byung Kyu Park, Sun Young Won, \\ Jeong Hun Seo, Chun Kyon Lee, Yong Suk Cho
}

Department of Internal Medicine, National Health Insurance Service Ilsan Hospital, Goyang, Korea

Received October 15, 2021

Revised November 22, 2021

Accepted November 22, 2021

Corresponding author:

Yong Suk Cho

E-mail: cho6706@nhimc.or.kr

https://orcid.org/0000-0002-3993-7891
Background/Aims: Colonic stenting as a bridge to elective surgery is an alternative for emergency surgery in patients with acute malignant colonic obstruction. However, since its benefits are uncertain, we aimed to establish whether it has better clinical outcomes.

Methods: The patients with acute malignant left-sided colon obstruction enrolled from January 2009 to December 2018 in National Health Insurance Service Ilsan Hospital. The patients were enrolled to undergo colonic stenting as a bridge to elective surgery or emergency surgery. The following oncological outcomes were assessed: incidence of complete remission, disease progression, local recurrence, and systemic recurrence.

Results: Out of 40 patients, 33 received self-expanding metallic stent (SEMS) as a bridge-tosurgery, and 7 underwent emergency surgery. More stoma was made in case of emergency surgery with statistical significance $(\mathrm{p}<0.001)$. There were no significant differences in complete remission rate in curable left-sided malignant colonic obstruction between SEMS as a bridgeto-surgery and emergency surgery. Complete remission was achieved for 3 patients $(42.9 \%)$ in the non-stent group and 27 patients $(81.8 \%)$ in the stent group. There was no statistically significant difference in oncologic outcomes between the two groups $(p=0.069)$. According to multi-variate analysis, advanced TNM stage, Adjuvant chemotherapy, and SEMS bridge-tosurgery were significantly associated with disease-free survival. Disease-free survival rate differed significantly between the two groups $(\mathrm{p}=0.024)$.

Conclusions: SEMS as a bridge-to-surgery might be an effective strategy and reduce stoma formation in acute malignant left-sided colon obstruction.

Key Words: Colon cancer; Colonic obstruction; Self expandable metallic stent; Emergency treatment; Surgery

\section{INTRODUCTION}

The European Society of Gastrointestinal Endoscopy has not recommended the placement of self-expanding metallic stent (SEMS) as a bridge to elective surgery in left-sided malignant colonic obstruction with high-quality evidence [1]. This is because the stent placement may have a potential oncological risk accompanying touched malignant cell seeding. In the existing guidelines, stent placement can be considered in those with an increased risk of postoperative mortality (patients more than 70 years old, or those with an American Society of Anesthesiologists physical status $\geq$ III) [1].

In cases of curable obstructive left-sided colon cancer, post-operative outcomes and treatment superiority of SEMS as bridge-to-surgery has not been proved clearly. Moreover, local disease recurrence and overall recurrence rate were significantly higher in SEMS replacement as a bridge-tosurgery; however, these studies were randomized controlled

Copyright (C) Korean Society of Gastrointestinal Cancer Research. 
trials with smaller samples [2-4].

However, considering the difficulty of tumor manipulation in distended bowels, decreased success rate of primary anastomosis, stoma-related complications including stoma prolapse after step-wise surgery (additional procedure for stoma reversal), and overall post-operative morbidity and mortality, many clinicians have tried SEMS as bridge-to-surgery and as an alternative treatment to emergency surgery in curable obstructive left-sided colon cancer [5]. Currently, several studies have been reported about the same [6,7]. There were a few studies comparing SEMS as bridge-tosurgery with emergency surgery for clinical outcomes and oncological outcomes, but they have the limitations of small sample size and potential selection bias [2-4].

Therefore, this study aims to compare the post-operative clinical outcomes of patients with left-sided malignant colonic obstruction that received SEMS as bridge-to-surgery with those that received emergency surgery.

\section{MATERIALS AND METHODS}

\section{Patients}

In this retrospective study from the National Health Insurance Service (NHIS) Ilsan Hospital, 50 patients diagnosed with curable left-sided malignant colonic obstruction from January 2009 to December 2018 were enrolled and analyzed. We defined curable status as 'surgically resectable status' in this study. Eligibility criteria included histopathologically proved left-sided colon cancer (from distal transverse colon to rectosigmoid junction) accompanying obstruction initially. All patients underwent either elective surgery after SEMS placement or emergency surgery. Patients were excluded if they had undergone SEMS placement due to a nonmalignant colonic obstruction, like extraluminal obstruction caused by other intraabdominal malignancies, if they were treated with palliative chemotherapy or supportive care, and if they had a history of any cancer, hereditary nonpolyposis colorectal cancer, or familial adenomatous polyposis.

\section{Self-expanding Metallic Stents Insertion}

SEMS insertion was performed under fluoroscopy and endoscopy-guided visualization. We used Niti-S uncovered colorectal stents (Taewoong Medical, Gimpo, Korea). Endoscopy was inserted till the distal margin of the malignant obstructive lesion; thereafter, a catheter was inserted through the stricture via endoscopy channel. Then, a floppy-tipped guide wire was inserted through the catheter, followed by SEMS deployment.

\section{Surgical Methods}

We reviewed the medical records and follow-up histories of each patient. All patients underwent surgical resection. Based on the tumor location and area involved, the surgical method was decided. Lower anterior resection, anterior resection, left hemicolectomy, right hemicolectomy, subtotal colectomy, or Hartmann's procedure was performed for curative resection. In case of failed primary anastomosis, a stoma was made. For all patients who underwent surgery, pathologic tumor, lymph node, and metastasis (TNM) stages were reset according to the final pathological report. In most of the cases, SEMS bridge-to-surgery was performed as initial treatment. However, in case of SEMS placement failure, expectation of impending bowel perforation, or suspected concealed bowel perforation, emergency surgery was carried out.

\section{Outcomes and Statistical Analysis}

Clinical data and test results of patients were collected from the time they were diagnosed with colon cancer and followed up with regular colonoscopy, abdominal computed tomography, and chest radiography during the whole study period or until death. Patients were divided into two groups, the group that received SEMS as bridge-to-surgery (stent group) and the group that underwent emergency surgery (non-stent group), and the following oncological outcomes were assessed: incidence of complete remission, disease progression, local recurrence, and systemic recurrence. 
The data were described using the frequency of the total for categorical variables and the mean and standard deviation for continuous variables. Independent $t$ testing was used for continuous variables. A chi-squared test was used to analyze the variables in a contingency table. To verify significance and disease-free survival rate of SEMS bridge-to-surgery, survival curves were plotted using the Kaplan-Meier method. In addition, we performed univariate analysis using the log-rank test to evaluate disease-free survival associated with treatment methods in patients that underwent SEMS bridgeto-surgery and in patients that underwent emergency surgery. Univariate and multivariate logistic regression analyses were performed to evaluate risk factors associated with poor prognosis. All the statistical analyses were performed with the statistical analysis software program SPSS, version 18 (IBM Co., Armonk, NY, USA). p < 0.05 was considered statistically significant.

This study was approved by the Institutional Review Board of NHIS Ilsan Hospital, Korea (IRB No. 2020-03-041). To guarantee the confidentiality of the data and records, we adhered to the Ethical Principles for Human Research defined by the 1964 Declaration of Helsinki, revised and updated by the World Health Organization (Fortaleza 2000). All the data used in this study were routinely collected from the NHIS database. Therefore, informed consent was not required.

\section{RESULTS}

Out of the 50 patients enrolled, 40 patients (20 males and females each) with curable left-sided malignant colonic obstruction were ultimately identified for our study.

The mean diagnostic age and average length of hospital stay in the non-stent group and stent group were similar between groups. There were no differences in sex, tumor location, histopathology, carbohydrate antigen 19-9 (CA19-9) level, cancer stage, lymphovascular invasion, and adjuvant chemotherapy between the two groups. More stoma was made in case of emergency surgery with statistically significance. The level of carcinoembryonic antigen (CEA) and lymph node metastasis was statistically significantly higher in the stent group. There was a significant difference in surgical methods between the two groups.

Seven patients underwent emergency surgery (non-stent group) and thirty-three patients underwent SEMS bridgeto-surgery (stent group) (Table 1). The technical success rate of SEMS placement was 91.7\% (33 of 36). Complications associated with SEMS occurred in three patients $(8.3 \%)$ in the stent group.

Two patients underwent SEMS insertion initially and were converted to emergency surgery due to bowel perforation during stent-procedure. One patient also had undergone SEMS insertion initially but underwent emergency surgery due to delayed bowel perforation after the SEMS procedure.

There was no statistically significant difference in oncologic outcome between the two groups in terms of complete remission, disease progression, and local recurrence (Table 2). Follow up loss included 3 cases in the stent group.

Regarding prognostic factors, adjuvant chemotherapy and SEMS insertion were found to be significantly associated with disease-free survival based on the univariate analyses (Table 3). Based on multi-variate analysis for variables considered significant in the univariate analysis, advanced TNM stage, adjuvant chemotherapy, and SEMS bridge-to-surgery were significantly associated with disease-free survival (Table 3).

Disease-free survival rate was found to be significantly different between the two groups ( $p=0.024)$ (Fig. 1). An estimated median disease-free survival was 2,739 days ( $95 \%$ confidence interval [CI] 0-5,885 days) in SEMS bridgeto-surgery group and 1,289 days (95\% CI 0-2,587 days) in the emergency surgery group. Significantly longer median disease-free survival for SEMS bridge-to-surgery group was confirmed $(\mathrm{p}=0.024)$.

\section{DISCUSSION}

In the case of malignant-colonic obstruction, emergency surgery could be associated with mortality in $15-34 \%$ of patients and morbidity in 32-64\%, despite advances in perioperative care. To decrease perioperative morbidity and increase the success rate of primary anastomosis, many 
Table 1. Histopathological and Clinical Characteristics of the Patients

\begin{tabular}{|c|c|c|c|}
\hline Characteristic & Non-stent group $(\mathrm{n}=7)$ & Stent group $(\mathrm{n}=33)$ & p-value \\
\hline Mean age (yr) & $67.1 \pm 22.1$ & $69.3 \pm 12.9$ & 0.730 \\
\hline Sex, male & 4 & 16 & 1.000 \\
\hline Average length of hospital stay & $21.1 \pm 10.7$ & $30.1 \pm 22.9$ & 0.130 \\
\hline \multicolumn{4}{|l|}{ Tumor location } \\
\hline RSJ & 0 & 1 & \multirow[t]{4}{*}{0.776} \\
\hline Sigmoid & 6 & 23 & \\
\hline Descending & 1 & 6 & \\
\hline Transverse & 0 & 3 & \\
\hline Stoma formation & 5 & 2 & $<0.001$ \\
\hline \multicolumn{4}{|l|}{ Histology } \\
\hline WD & 2 & 10 & \multirow[t]{3}{*}{0.529} \\
\hline MD & 3 & 19 & \\
\hline $\mathrm{PD} /$ mucinous & 2 & 4 & \\
\hline CEA & $1.2 \pm 0.9$ & $6.1 \pm 7.9$ & 0.001 \\
\hline CA19-9 & $18.9 \pm 18.6$ & $15.2 \pm 21.0$ & 0.685 \\
\hline \multicolumn{4}{|l|}{ TNM classification } \\
\hline \multicolumn{4}{|l|}{ T stage } \\
\hline T3 & 4 & 25 & \multirow[t]{2}{*}{0.369} \\
\hline $\mathrm{T} 4$ & 3 & 8 & \\
\hline \multicolumn{4}{|l|}{$\mathrm{N}$ stage } \\
\hline N0 & 1 & 17 & \multirow[t]{3}{*}{0.004} \\
\hline N1 & 6 & 7 & \\
\hline N2 & 0 & 9 & \\
\hline Stage II & 1 & 17 & 0.205 \\
\hline Stage III & 6 & 16 & \\
\hline \multicolumn{4}{|l|}{ Lymphovascular invasion } \\
\hline Yes & 6 & 25 & \multirow[t]{2}{*}{1.000} \\
\hline No & 1 & 8 & \\
\hline \multicolumn{4}{|l|}{ Surgical method } \\
\hline LAR & 1 & 5 & \multirow[t]{6}{*}{$<0.001$} \\
\hline AR & 1 & 17 & \\
\hline Left hemicolectomy & 0 & 6 & \\
\hline Right hemicolectomy & 0 & 4 & \\
\hline Subtotal colectomy & 1 & 0 & \\
\hline Hartmann's procedure & 4 & 1 & \\
\hline \multicolumn{4}{|l|}{ Adjuvant chemotherapy } \\
\hline No & 2 & 8 & \multirow[t]{2}{*}{1.000} \\
\hline Yes & 5 & 25 & \\
\hline
\end{tabular}

Values are presented as mean \pm standard deviation or number only. RSJ, rectosigmoid Junction; WD, well differentiated carcinoma; MD, moderately differentiated carcinoma; PD, poorly differentiated carcinoma; CEA, carcinoembryonic antigen; CA19-9, carbohydrate antigen 19-9; LAR, lower anterior resection; AR, anterior resection.

clinical trials were challenged [8-11]. Recently, many studies have been conducted comparing the clinical and oncological outcome of SEMS as a bridge-to-surgery and emergency surgery. However, there is no definitively superior evidence of SEMS as a bridge-to-surgery until now.

The cohort size of the non-stent group is relatively small.
Hence, this might have resulted in the absence of a significant difference in the oncological outcomes between the two groups, although non-stent group has a significantly lower lymph node metastasis stage.

Clinical success rate of SEMS insertion is about $70 \%$ according to recent meta-analysis study. Procedure and stent- 
Table 2. Oncologic Outcomes (Non-stent Group vs. Stent Group)

\begin{tabular}{lcrc}
\hline \multicolumn{1}{c}{ Outcome } & Non-stent group $(\mathrm{n}=7)$ & Stent group $(\mathrm{n}=33)$ & $\mathrm{p}$-value \\
\hline Complete remission & 3 & 27 & 0.069 \\
Disease progression & 3 & 2 & \\
Local recurrence & 1 & 0 & $<0.001$ \\
Systemic recurrence & 0 & 1 & 3 \\
F/U loss & 0 & 3 & $<$ \\
\hline
\end{tabular}

Values are presented as number only. F/U, follow up.

Table 3. Univariate and Multivariate Analysis of Prognostic Factors

\begin{tabular}{|c|c|c|c|c|c|c|}
\hline \multirow[b]{2}{*}{ Factor } & \multicolumn{3}{|c|}{ Univariate analysis } & \multicolumn{3}{|c|}{ Multivariate analysis } \\
\hline & Hazard ratio & $\begin{array}{l}\text { Confidence } \\
\text { interval 95\% }\end{array}$ & p-value & Hazard ratio & $\begin{array}{l}\text { Confidence } \\
\text { interval 95\% }\end{array}$ & p-value \\
\hline \multicolumn{7}{|c|}{ TNM classification } \\
\hline $\begin{array}{l}\text { II } \\
\text { III }\end{array}$ & 6.933 & $0.866-55.4880$ & 0.068 & 99.9 & $5.61-1,782.6$ & 0.002 \\
\hline \multicolumn{7}{|c|}{ Adjuvant chemotherapy } \\
\hline $\begin{array}{l}\text { Yes } \\
\text { No }\end{array}$ & 9.281 & $2.297-37.494$ & 0.002 & 631.7 & $12.0-33,217.9$ & 0.001 \\
\hline \multicolumn{7}{|l|}{ Stent insertion } \\
\hline $\begin{array}{l}\text { Yes } \\
\text { No }\end{array}$ & 0.247 & $0.066-0.923$ & 0.038 & 24.1 & $1.6-359.6$ & 0.021 \\
\hline
\end{tabular}

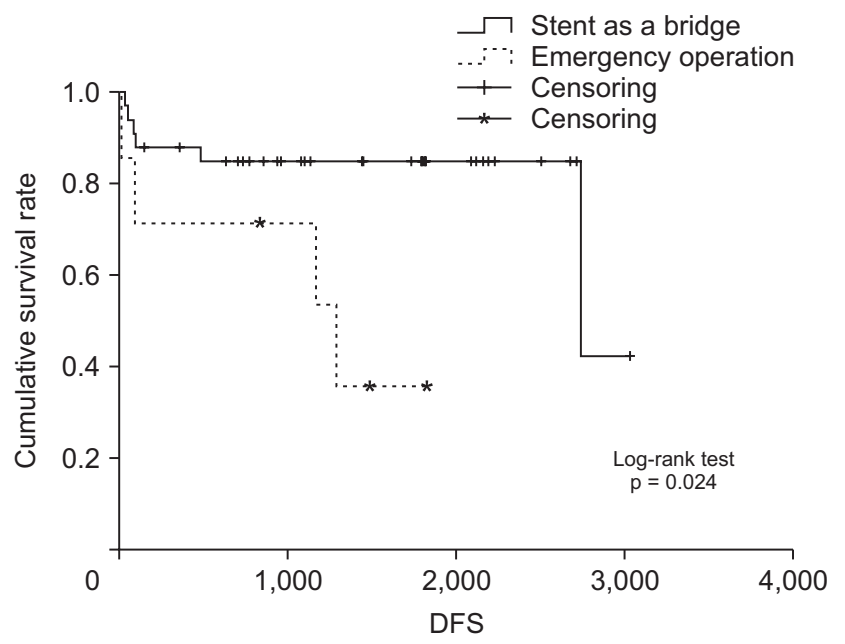

Fig. 1. Kaplan-Meyer's curve for stent as bridge-to-surgery vs. emergency surgery. DFS, disease free survival.

related complications were observed in $5-23.1 \%$ of patients, with stent-related perforations reported in $5 \%$ patients [12]. In our study, the technical success rate of SEMS placement was $91.7 \%$ (failed 3 cases out of a total 36 cases), and it was not inferior to the general success rate in the previous stud- ies. So, the possibility that operator's bias of technical success rate of SEMS placement effect on the oncological outcomes of emergent surgery is not high.

Advanced TNM stage is one of the known poor prognostic factors. So, we analyzed multivariate study including TNM stage, although TNM stage did not affect the prognosis in our univariate analysis (Table 3). As a result of multivariate analysis, disease-free survival was significantly longer in the SEMS as a bridge-to-surgery group, and adjuvant chemotherapy and advanced TNM stage seemed to influence this. TNM stage and adjuvant chemotherapy show a strong relationship with prognosis in the multivariate analysis. Therefore, under SEMS as a bridge-to-surgery, adjuvant chemotherapy and TNM stage can be important prognostic factors.

Moreover, there was a significant difference in the diseasefree survival between the two groups. This is a different result compared to some previous studies [2-4]. In a KaplanMeyer's curve, SEMS as a bridge-to-surgery group showed statistically significant higher disease-free survival. In our 
study, the stent group was found to show favorable oncological outcomes in conditions with earlier TNM stage and proper adjuvant chemotherapy, compared to the non-stent group. However, disease free survival was longer among patients with advanced TNM stage in this study. It is possible that this observation may be due to a statistical error caused by the small number of patients who were included for research analysis. Although TNM stage is the most important prognostic factor, it is possible that chemotherapy was not consistently performed for older adults and this may have influenced the outcome. Since mortality was included as an event in disease free survival, there may be mortalities from comorbidities among older adults, despite early TNM stage, and these factors are considered to have influenced the results. One study showed that colonic obstruction in patients with right-sided colorectal cancer had a worse prognosis in TNM stage II despite similar disease stage [13]. It is suggested that the clinical characteristics of colorectal cancer that cause colon obstruction may have caused the difference in prognosis.

However, there were several limitations in this study. Firstly, the present study was not a randomized controlledtrial, but a retrospective study conducted in a single institution. Secondly, there was a potential selection bias. Emergency surgery was performed in very limited cases, when impending perforation was expected, for suspected concealed perforations, and for failed SEMS placements. Out of 7 cases, 3 (42.9\%) received emergency surgery due to SEMS procedure-related complication, such as a bowel perforation. SEMS procedure-related complication could induce touched malignant cell seeding, causing a poor prognosis of oncological outcomes in the emergency surgery group. Thirdly, the cohort size was relatively small. There were only 7 cases in the non-stent group, compared to 33 cases in the stent- group. For a similar reason, in the previous multicenter randomized trial study, colonic stenting as a bridgeto-elective surgery had no decisive clinical advantages to emergency surgery [14]. Thus, randomized controlled trials with a large cohort are warranted.

The stent group showed a significantly lower stoma formation rate after the initial surgery ( 2 out of 33 patients vs.
5 out of 7 patients, $\mathrm{p}=0.001$ ). The presence of edematous colonic tissue resulting from intestinal obstruction often makes bowel manipulation in the operation field difficult. In an acute colonic obstruction, SEMS placement can be an effective solution for relieving edematous tissue change. It can also be helpful for reducing postoperative mortality and morbidity rates and increasing the success rate for primary anastomosis, considering that emergency operation is usually performed under the poor general condition of patients, and has a high mortality and morbidity rate [15].

In conclusion, there was no significant difference in complete remission rate in curable left-sided malignant colonic obstruction between SEMS as a bridge-to-surgery and emergency surgery. The SEMS bridge-to-surgery group showed a significantly longer median disease-free survival. Advanced TNM stage and adjuvant chemotherapy could be prognostic factors of the SEMS as a bridge-to-surgery group. SEMS as a bridge-to-surgery can be an effective strategy and reduce stoma formation.

\section{ACKNOWLEDGEMENTS}

This study used the National Health Insurance Service (NHIS) 2009-2018 database (NHIS 2020-03-041). The authors alone are responsible for the content and writing of the article.

\section{CONFLICTS OF INTEREST}

No potential conflict of interest relevant to this article was reported.

\section{AUTHOR'S CONTRIBUTIONS}

Conceptualization: Yong Suk Cho, Eun Ju Choe. Data acquisition: Yong Kang Lee, Han Ho Jeon, Sun Young Won, Jeong Hun Seo. Formal analysis: Jong Won Choi, Chun Kyon Lee, Byung Kyu Park. Supervision: Yong Suk Cho. Writing original draft: Eun Ju Choe. Writing review \& editing: Yong Suk Cho, Eun Ju Choe. 


\section{ORCID}

Eun Ju Choe, https://orcid.org/0000-0002-0012-472X

Yong Kang Lee, https://orcid.org/0000-0003-2929-4447

Han Ho Jeon, https://orcid.org/0000-0002-5207-8761

Jong Won Choi, https://orcid.org/0000-0001-9546-7313

Byung Kyu Park, https://orcid.org/0000-0002-6801-3831

Sun Young Won, https://orcid.org/0000-0001-7344-8007

Jeong Hun Seo, https://orcid.org/0000-0002-1063-0247

Chun Kyon Lee, https://orcid.org/0000-0002-8492-2883

Yong Suk Cho, https://orcid.org/0000-0002-3993-7891

\section{REFERENCES}

1. van Hooft JE, van Halsema EE, Vanbiervliet G, et al. Self-expandable metal stents for obstructing colonic and extracolonic cancer: European Society of Gastrointestinal Endoscopy (ESGE) clinical guideline. Gastrointest Endosc 2014;80:747-761.e1-e75.

2. Tung KL, Cheung HY, Ng LW, Chung CC, Li MK. Endolaparoscopic approach versus conventional open surgery in the treatment of obstructing left-sided colon cancer: long-term follow-up of a randomized trial. Asian J Endosc Surg 2013;6:78-81.

3. Alcántara M, Serra-Aracil X, Falcó J, Mora L, Bombardó J, Navarro S. Prospective, controlled, randomized study of intraoperative colonic lavage versus stent placement in obstructive left-sided colonic cancer. World J Surg 2011; 35:1904-1910.

4. Gorissen KJ, Tuynman JB, Fryer E, et al. Local recurrence after stenting for obstructing left-sided colonic cancer. Br J Surg 2013;100:1805-1809.

5. Veld JV, Amelung FJ, Borstlap WAA, et al. Comparison of decompressing stoma vs stent as a bridge to surgery for left-sided obstructive colon cancer. JAMA Surg 2020;155:206-215.

6. Ballestero Pérez A, García Pérez JC, Muriel A, Die Trill J, Lobo E. The long-term recurrence rate and survival of obstructive left-sided colon cancer patients: a stent as a bridge to surgery. Rev Esp Enferm Dig 2018;110:718725.
7. Abdussamet Bozkurt M, Gonenc M, Kapan S, Kocatasş A, Temizgönül B, Alis H. Colonic stent as bridge to surgery in patients with obstructive left-sided colon cancer. JSLS 2014;18:e2014.00161.

8. Smothers L, Hynan L, Fleming J, Turnage R, Simmang C, Anthony T. Emergency surgery for colon carcinoma. Dis Colon Rectum 2003;46:24-30.

9. Law WL, Choi HK, Chu KW. Comparison of stenting with emergency surgery as palliative treatment for obstructing primary left-sided colorectal cancer. Br J Surg 2003;90:1429-1433.

10. Martinez-Santos C, Lobato RF, Fradejas JM, Pinto I, Ortega-Deballón P, Moreno-Azcoita M. Self-expandable stent before elective surgery vs. emergency surgery for the treatment of malignant colorectal obstructions: comparison of primary anastomosis and morbidity rates. Dis Colon Rectum 2002;45:401-406.

11. Saida Y, Sumiyama Y, Nagao J, Uramatsu M. Long-term prognosis of preoperative "bridge to surgery" expandable metallic stent insertion for obstructive colorectal cancer: comparison with emergency operation. Dis Colon Rectum 2003;46(10 Suppl):S44-S49.

12. Tan CJ, Dasari BV, Gardiner K. Systematic review and meta-analysis of randomized clinical trials of selfexpanding metallic stents as a bridge to surgery versus emergency surgery for malignant left-sided large bowel obstruction. Br J Surg 2012;99:469-476.

13. Chin CC, Wang JY, Changchien CR, Huang WS, Tang R. Carcinoma obstruction of the proximal colon cancer and long-term prognosis--obstruction is a predictor of worse outcome in TNM stage II tumor. Int J Colorectal Dis 2010;25:817-822.

14. van Hooft JE, Bemelman WA, Oldenburg B, et al. Colonic stenting versus emergency surgery for acute left-sided malignant colonic obstruction: a multicentre randomised trial. Lancet Oncol 2011;12:344-352.

15. Small AJ, Baron TH. Comparison of Wallstent and Ultraflex stents for palliation of malignant left-sided colon obstruction: a retrospective, case-matched analysis. Gastrointest Endosc 2008;67:478-488. 